\title{
One-Pot Polymerase Chain Reaction with Gold Nanoparticles for Rapid and Ultrasensitive DNA Detection
}

\author{
Miao Cai, Feng Li, Yan Zhang, and Qiangbin Wang ( $\varangle)$ \\ $i$-Lab, Suzhou Institute of Nano-Tech and Nano-Bionics, Chinese Academy of Sciences, Suzhou 215123, China \\ Received: 13 May 2010 / Accepted: 12 June 2010 \\ (C) The Author(s) 2010. This article is published with open access at Springerlink.com
}

\begin{abstract}
We report a novel method for rapid, colorimetric detection of a specific deoxyribonucleic acid (DNA) sequence by carrying out a polymerase chain reaction in the presence of gold nanoparticles functionalized with two primers. Extension of the primers when the target DNA is present as a template during the polymerase chain reaction process affords the complementary sequences on the gold nanoparticle surfaces and results in the formation of gold nanoparticle aggregates with a concomitant color change from red to pinkish/purple. This method provides a convenient and straightforward solution for ultrasensitive DNA detection without any further post-treatment of the polymerase chain reaction products being necessary, and is a promising tool for rapid disease diagnostics and gene sequencing.
\end{abstract}

\section{KEYWORDS}

deoxyribonucleic acid (DNA) detection, polymerase chain reaction (PCR), Au nanoparticle, colorimetric

\section{Introduction}

The area of molecular diagnostics is at the forefront of modern bioanalytical research. The ability to detect trace amounts of target deoxyribonucleic acid (DNA) sequences in a highly selective manner is of evergrowing interest for rapid detection of disease [1-11]. Herein, we report a method for rapid detection of DNA with ultrahigh sensitivity and specificity based on a novel strategy involving a combination of a polymerase chain reaction (PCR) and Au nanoparticles (Au NPs). Au NPs, with their extraordinarily high extinction coefficient, show controllable optical properties which are strongly dependent on the particle size and interparticle distance. The aggregation of
$\mathrm{Au}$ NPs causes a significant shift in the extinction spectrum as the solution color changes from red to purple $[2,8,9]$. The clearly distinguishable color change facilitates a very simple sensor readout which can be performed by the naked eye. The use of controllable aggregation of Au NPs was pioneered by Mirkin et al., harnessing DNA hybridization to induce an assembly of particles modified with single-stranded DNA (ssDNA) $[12,13]$. PCR is a revolutionary technique in molecular biology and medical sciences, possessing both high sensitivity and high selectivity $[14,15]$. The minimum amount of the target sequence required in PCR could be as few as 1000 copies, which is far below the detection limit of other technologies. The high selectivity of PCR can be realized by different

Address correspondence to qbwang2008@sinano.ac.cn 
design of forward and reverse primer sequences which result from different target sequences. However, posttreatment of the PCR products by processes such as gel electrophoresis is time-intensive, and does not allow the rapid detection of target DNA. Real-time PCR - as a more advanced technique-is used to amplify and simultaneously quantify a targeted DNA molecule, which enables both detection and quantification of one or more specific sequences in a DNA sample. However, for real-time PCR methods based on a fluorescent intercalator, dyes such as SYBR Green will bind to all double-stranded DNA (dsDNA) PCR products, including nonspecific PCR products. This will potentially interfere with, or prevent, accurate quantification of the intended target sequence [16].

Our concept for rapid and ultrasensitive detection of specific DNA sequences is based on amplified $\mathrm{Au}$ NP aggregation via PCR as shown in Scheme 1. In detail, $13 \mathrm{~nm} \mathrm{Au} \mathrm{NPs} \mathrm{are} \mathrm{functionalized} \mathrm{with} \mathrm{two}$ kinds of thiolated DNA sequences, forward primer and reverse primer. The forward primer is the same as part of the target DNA sequence and the reverse primer is complementary to the other part of the target DNA sequence (for sequence information, see the Experimental section). Note that the two primers have minimal base pairing between each other, so that no aggregation of Au NPs is observed before PCR reaction, as shown by the UV-visible absorbance peak at $519 \mathrm{~nm}$. During the PCR process, extension of the reverse primer by rTaq DNA polymerase with the target DNA as a template will produce the complementary sequences on the Au NP surfaces, and result in the formation of a polymeric network of Au NPs. Aggregation of the Au NPs causes a red shift of the UV-visible absorbance, which enables ultrasensitive real-time DNA detection when UVvisible spectroscopy is employed during the PCR procedure. In addition, the concomitant color change from red to pinkish/purple can be observed by the naked eye. This method provides a convenient and straightforward solution for ultrasensitive DNA detection without any further post-treatment of the PCR products being required.

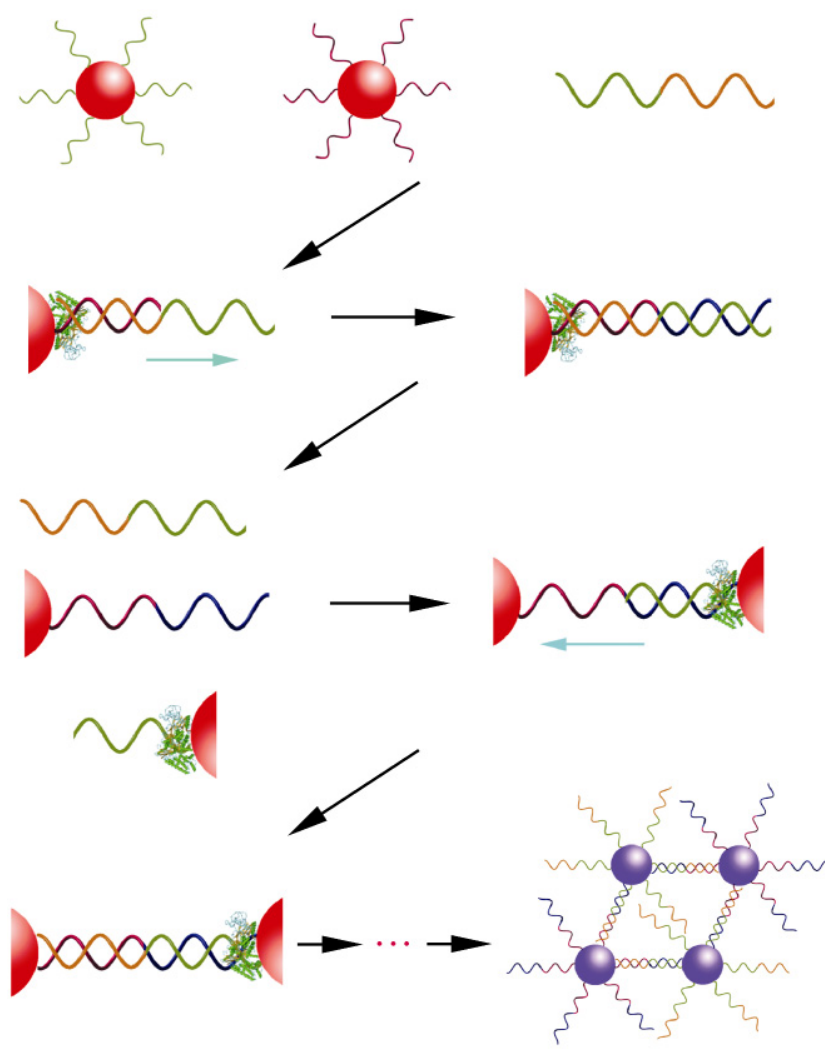

Forward primer: $\backsim$ Reverse primer: $\curvearrowright$

Target: $\sim$

Scheme 1 Schematic illustration of the Au NPs involved in the PCR process

\section{Experimental}

\subsection{Reagents and apparatus}

Synthetic 5'-modified forward and reverse primers were obtained from Shanghai Sangon Co., Ltd. PCR kits were purchased from Takara Co., Ltd. Hydrogen tetrachloroaurate $\left(\mathrm{HAuCl}_{4}\right)$ and sodium citrate were purchased from Sigma-Aldrich and used without further purification. Ultrapure water $(18.2 \mathrm{M} \Omega)$ was produced by Millipore Academic. UV-visible spectra were recorded on a PerkinElmer Lambda 25 UV-Vis Spectrometer. Transmission electronic microscopy (TEM) images were obtained on a Tecnai G2 F20 S-Twin TEM.

\subsection{DNA primer design and synthesis}

The primer sequences used in experiments were: 
forward primer, 5'-SH-C6-GACAGGCCCGAAGGA ATAGA-3'; reverse primer, 5'-SH-C6-CTCTCTCTCC ACCTTCTTCT-3'; target: 5'-GACAGGCCCGAAGGA ATAG AAGAAGAAGGTGGAGAGAGAG-3'; random non- target sequence, 5'-CACGGTGCTCTGAGTTCA ACCTGGCCTACGAGCCGGATCA-3'.

\subsection{Particle synthesis and functionalization}

$\mathrm{Au}$ NPs with an average diameter of $13 \mathrm{~nm}$ were prepared by citrate reduction of $\mathrm{HAuCl}_{4}$ according to the Ref. [17]. The NP size was confirmed by TEM. The concentration of Au NPs was determined by UVvisible absorbance at $519 \mathrm{~nm}$ (extinction coefficient $=$ $\left.3.64 \times 10^{8} \mathrm{~L} \cdot \mathrm{mol}^{-1} \cdot \mathrm{cm}^{-1}\right)$. Functionalization of Au NPs with thiolated forward and reverse primers was performed by addition of DNA to the Au NPs solution. The mixture was then left at room temperature to incubate overnight. To remove any unbound DNA, the particles were centrifuged, and the pellet was collected and resuspended in ultrapure water. Centrifugation was repeated until all unbound DNA was removed from the mixture.

\subsection{Primer extension via PCR}

The PCR reaction was performed in a $25 \mu \mathrm{L}$ mixture containing $1 \times$ Standard Taq Reaction Buffer $(50 \mathrm{mmol} / \mathrm{L}$ $\mathrm{KCl}, 10 \mathrm{mmol} / \mathrm{L}$ Tris- $\mathrm{HCl} \mathrm{pH} 9.0$ at $25{ }^{\circ} \mathrm{C}$, and $1.5 \mathrm{mmol} / \mathrm{L} \mathrm{MgCl}_{2}$ ), $2 \mathrm{mmol} / \mathrm{L}$ each of four deoxynucleotidetriphosphates (dNTPs), $5 \mathrm{ng}$ of target sequences, and $0.5 \mathrm{U}$ of rTaq DNA polymerase. About $20 \mathrm{pmoL}$ each of the Au-primer conjugates instead of the pure primer were used in PCR. The PCR reaction was performed in a Bio-Rad PCR system (Bio-Rad, USA). The amplifying procedure of the PCR was: (1) $2 \mathrm{~min}$ at $94{ }^{\circ} \mathrm{C}$; (2) 5, 10, 15, 20, 25, and 30 cycles of $30 \mathrm{~s}$ at $94{ }^{\circ} \mathrm{C}$, $30 \mathrm{~s}$ at $55^{\circ} \mathrm{C}$, and $30 \mathrm{~s}$ at $72{ }^{\circ} \mathrm{C}$; (3) 3 min at $72{ }^{\circ} \mathrm{C}$.

\subsection{TEM imaging}

Samples for TEM analysis were prepared by drying a drop of the PCR mixture on amorphous carbon-coated copper grids.

\section{Results and discussion}

As a proof-of-concept experiment, HIV gp140 exon was selected as the detection target sequence for the sensor system. After 30 cycles of PCR, the UV-visible spectrum of the reaction mixture showed a red-shift from $519 \mathrm{~nm}$ to $526 \mathrm{~nm}$ (Fig. 1(a)). A clear color change from red to purple was also observed (Fig. 1(b)). The color change from red to purple indicates the association of Au NPs via hybridization of extended primer DNA. The aggregation of Au NPs was further confirmed by TEM. As shown in Fig. 1(c), massive agglomeration was observed after PCR, in contrast to the randomly dispersed NPs present before PCR.

The concentration of $\mathrm{Mg}^{2+}$ in the PCR mixture solution is crucial to our detection system. rTaq DNA polymerase cannot function without appropriate amounts of $\mathrm{Mg}^{2+}$ present in the reaction mixture. However, the presence of high concentrations of $\mathrm{Mg}^{2+}$ will induce the aggregation of Au NPs in the solution. Hence, the appropriate concentration of $\mathrm{Mg}^{2+}$ in the PCR reaction mixture was systematically determined using a series of $\mathrm{Mg}^{2+}$ concentrations (0, 0.3, 0.6, 0.9, $1.2,1.5,1.8$, and $2 \mathrm{mmol} / \mathrm{L})$. rTaq showed optimal enzyme activity with an $\mathrm{Mg}^{2+}$ concentration around $1.5 \mathrm{mmol} / \mathrm{L}$. Usually, such a high concentration of $\mathrm{Mg}^{2+}$ will result in the agglomeration of Au NPs. Through a careful ligand-exchange process for Au NP surface functionalization [18-20], highly stable Au NPs were obtained with about 300 copies of DNA per Au NP, which are able to resist agglomeration in $1.5 \mathrm{mmol} / \mathrm{L}$ $\mathrm{Mg}^{2+}$. Meanwhile, $1.5 \mathrm{mmol} / \mathrm{L} \mathrm{Mg}^{2+}$ is ideal for maximum rTaq enzyme activity.

To evaluate the effect of $\mathrm{Mg}^{2+}$ and rTaq on the $\mathrm{Au}$ NP behavior during PCR, control experiments were carefully performed to exclude the possibility of any influence of $\mathrm{Mg}^{2+}$ and rTaq on the PCR results. Without the target DNA in the PCR mixture but with the same concentrations of $\mathrm{Mg}^{2+}$ and rTaq in the reaction mixture, we did not observe the absorbance peak shift and color change of the reaction mixture after PCR.

The specificity of our system was studied with a non-target DNA. We harnessed a randomly designed sequence (5'-CACGGTGCTCTGAGTTCAACCTGG CCTACGAGCCGGATCA-3') for our purpose. After the same PCR procedure, no UV-visible absorbance peak shift was observed. Nor did we witness any color change in the PCR tube. However, as with most techniques involving PCR, the specificity of our system

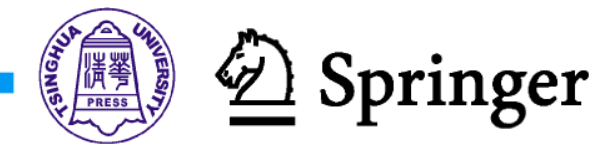




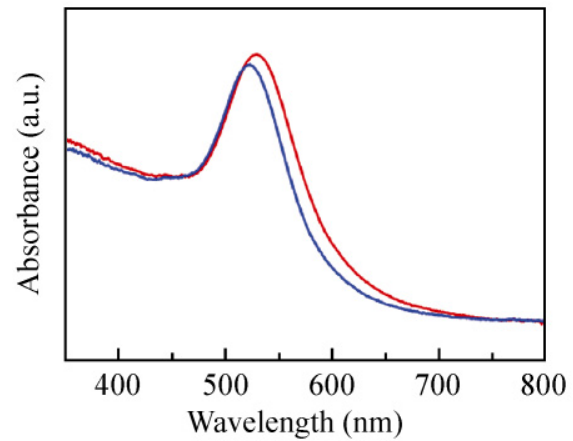

(a)

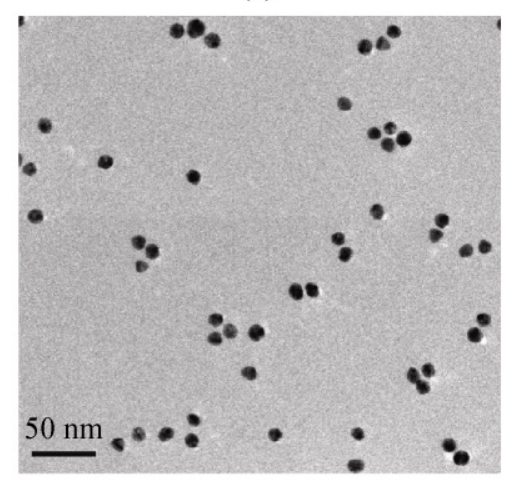

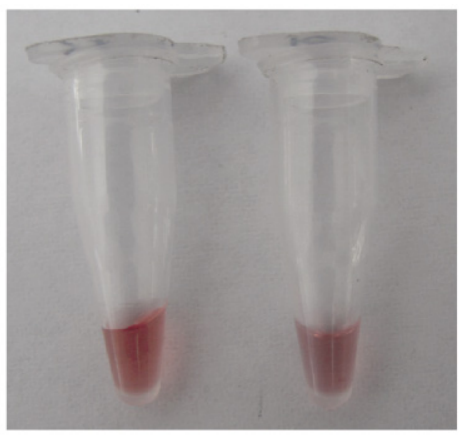

(b)

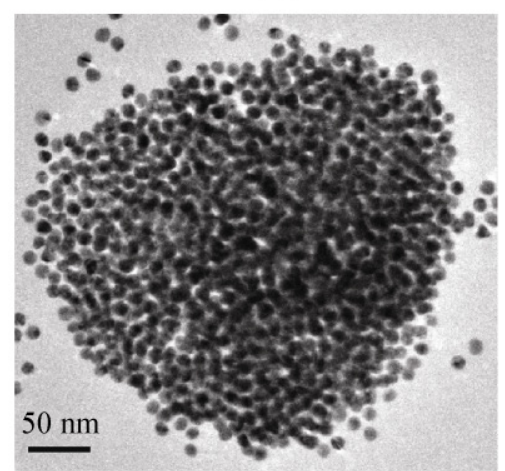

(c)

Figure 1 (a) UV-visible spectra of the PCR mixture before (blue curve, absorbance peak at $519 \mathrm{~nm}$ ) and after (red curve, absorbance peak at $526 \mathrm{~nm}$ ) PCR. (b) Photographs of the mixture before (left) and after (right) PCR. (c) TEM images of the mixture before (left) and after (right) PCR. Note that Au NPs are randomly distributed before PCR whereas a state of massive agglomeration is observed after PCR

relies largely on the PCR technique itself. To achieve a high specificity, careful design of the primer sequences is essential.

In a further set of experiments, we studied the correlation between the number of PCR cycles and the shift in the spectral maximum position in order to determine the shortest detection time. The degree of $\mathrm{Au}$ NP aggregation is expected to be influenced by the PCR products which serve as the linker molecules for forming the Au NP agglomeration. More cycles of the PCR procedure will lead to more PCR amplification which provides more linker molecules, and will result in a larger red-shift of UV-visible spectrum [21]. As expected, the spectral shift increased when the cycle number $N$ was increased from 5 to 20 in our experiments (Fig. 2). As shown in Fig. 2, there is a $2.3 \mathrm{~nm}$ red-shift of the absorbance peak of the PCR solution when 5 cycles were run. Therefore if UV-visible spectroscopy is employed for real time detection, the detection can be finished after 5 cycles of PCR, that is, in less than $15 \mathrm{~min}$.

However, the spectral shift ceased to increase after 20 cycles. This may possibly indicate that PCR has reached full capacity after 20 cycles and no more

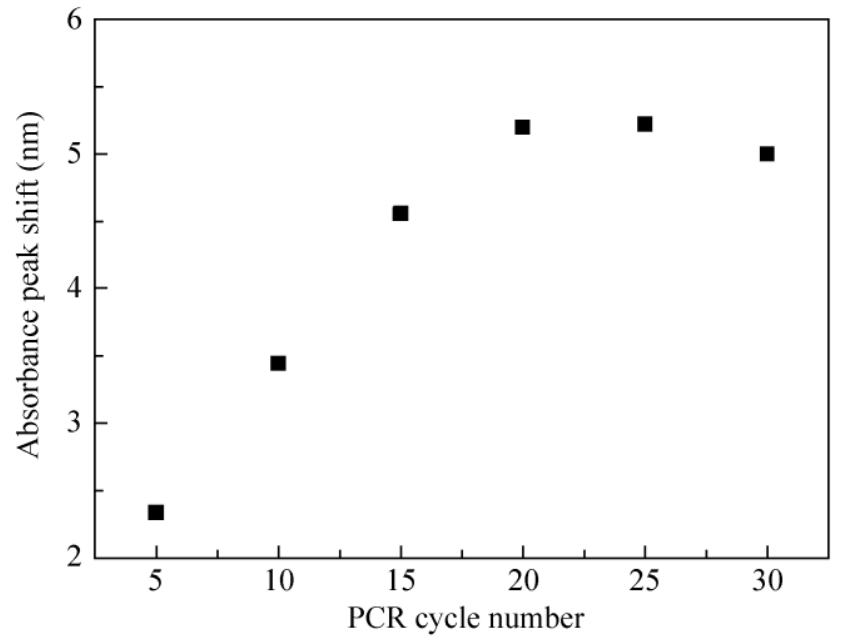

Figure 2 Correlation of the UV-visible absorbance peak shift with number of PCR cycles 
linker molecules are produced after 20 cycles of PCR. It is also possible that more linker molecules are still produced after 20 cycles, but cease to contribute to the aggregation and therefore aggregation of the $\mathrm{Au}$ NPs reaches the maximum possible extent after 20 cycles.

It is important to point out that the UV-visible absorbance peak shift may possibly be affected by a number of other factors besides the number of PCR cycles.

The plasmonic interaction between Au NPs is largely dependent on the size and interparticle distance of $\mathrm{Au}$ NPs. For Au NPs of a fixed size, the length of target DNA sequences plays an important role in determining the shift in the position of the spectral maximum [22-23]. Use of longer target sequences will result in a larger distance between Au NPs and hence, weaker plasmonic interactions and a smaller spectral shift. However, if the target sequence selected is too short, it is not ideal for application in DNA detection because the steric hindrance of the $3 \mathrm{~nm}$ sized rTaq polymerase adsorbed on Au NPs makes it difficult for short DNA to hybridize. We speculate that the target sequence should be at least 20 nucleotides (nt) $(\sim 6.8 \mathrm{~nm})$ in length to overcome the steric hindrance caused by rTaq polymerase. It turns out that the detection of a $40 \mathrm{nt}$ target in our experiment is feasible.

We also investigated the sensitivity of our detection system. A series of solutions containing various concentrations of target DNA sequences (5000, 500, 50, and $5 \mathrm{pmol} / \mathrm{L}$ ) were utilized in our experiments. The results are shown in Fig. 3. For the $5 \mathrm{pmol} / \mathrm{L}$ target DNA sequence test, we observed a $2 \mathrm{~nm}$ red-shift of the Au NP absorbance peak after 20 cycles of PCR. A larger spectral shift was observed with target concentrations above $50 \mathrm{pmol} / \mathrm{L}$ ( $3 \mathrm{~nm}$ for $50 \mathrm{pmol} / \mathrm{L}, 5 \mathrm{~nm}$ for $500 \mathrm{pmol} / \mathrm{L}$, and $6 \mathrm{~nm}$ for $5000 \mathrm{pmol} / \mathrm{L}$ ). Thus, the detection sensitivity of our system using $13 \mathrm{~nm} \mathrm{Au}$ NPs is on the pmol/L level when using UV-visible spectroscopy. With the naked eye, we can detect target DNA concentrations of $500 \mathrm{pmol} / \mathrm{L}$ as the color of the $\mathrm{Au}$ NP solution changed from red to purple. That is, we can detect 0.1 femtomole of target DNA with the help of UV-visible spectroscopy and 10 femtomoles of target DNA by the naked eye. Considering the $\mathrm{Au}$ NP size effect, the sensitivity of our system could be

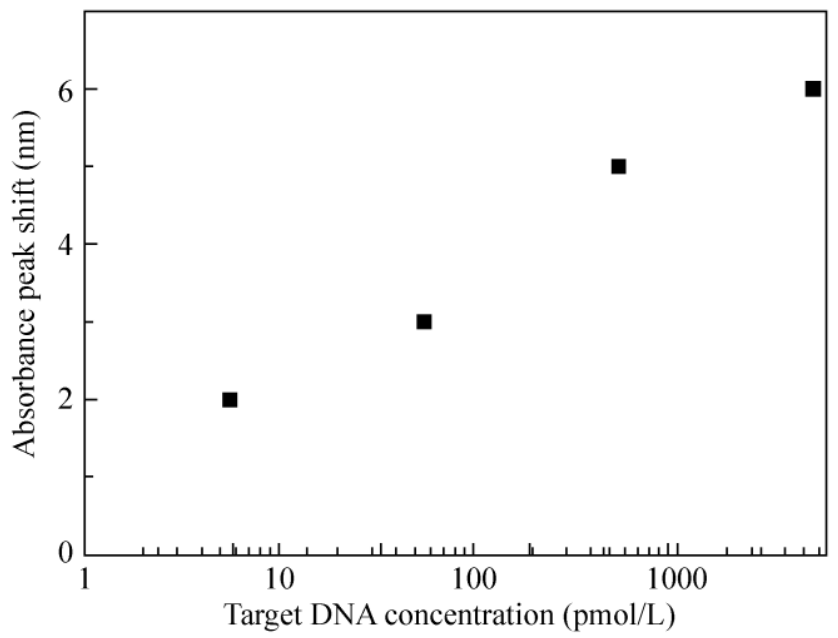

Figure 3 The correlation of UV-visible absorbance peak shift with initial target DNA concentration

further improved by employing larger Au NPs because the plasmonic interaction between larger Au NPs has been shown to be significantly stronger than for $13 \mathrm{~nm}$ Au NPs [24, 25].

So far, we have carefully studied the specificity, sensitivity and time response of our proposed $\mathrm{Au}$ NP/PCR system. The above results show that this novel method is rapid and ultrasensitive with high specificity for DNA detection. However, there is one concern that should be addressed: if we obtained the target DNA strands in the same concentration by PCR beforehand, what would happen when DNA primerfunctionalized Au NPs were added? Would the same shift of the absorbance spectrum be observed? We carefully carried out the necessary control experiment. As shown in Fig. 4, there is a negligible shift in the absorbance spectrum $(\sim 1 \mathrm{~nm})$ of the Au NPs solution before and after mixing with the same concentration of the target DNA strands; this is much smaller than that $(6 \mathrm{~nm})$ for the one-pot $\mathrm{Au}$ NP-involved PCR system. This demonstrates that the one-pot PCR with $\mathrm{Au}$ NPs is more sensitive in DNA detection than the two-step method.

\section{Conclusions}

We have demonstrated a novel method for rapid and ultrasensitive DNA detection. Adding primerconjugated Au NPs into the PCR system gives a convenient and straightforward method for ultrasensitive 


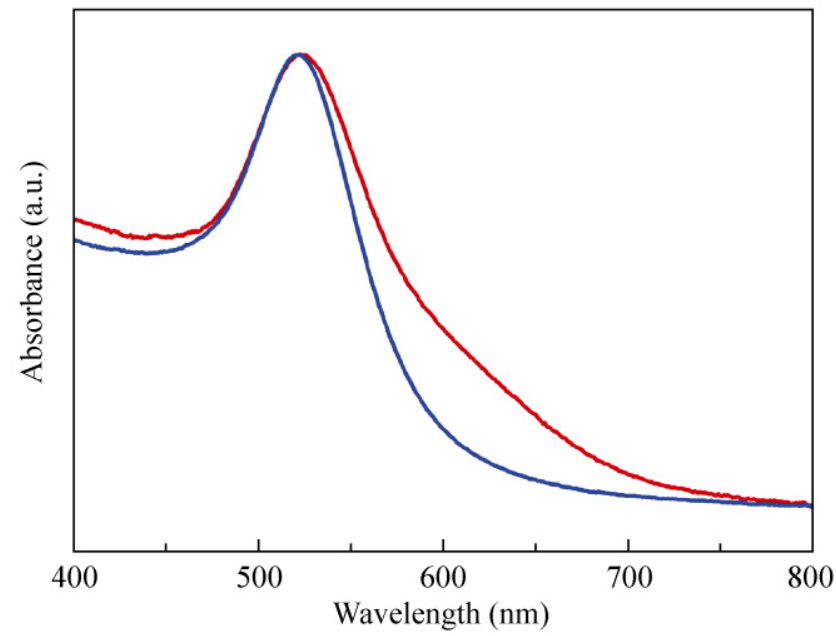

Figure 4 The UV-visible spectra of Au NPs without the PCR product (blue curve) and Au NPs with the PCR product (red curve)

DNA detection without any post-treatment of the PCR products being necessary. This rapid, ultrasensitive DNA detection method holds promise in disease diagnostics and gene sequencing.

\section{Acknowledgements}

This work was supported by the "Bairen Jihua" program of Chinese Academy of Sciences, the Chinese Academy of Sciences/State Administration of Foreign Experts Affairs (CAS/SAFEA) International Partnership Program for Creative Research Teams and Suzhou Bureau of Science and Technology.

Open Access: This article is distributed under the terms of the Creative Commons Attribution Noncommercial License which permits any noncommercial use, distribution, and reproduction in any medium, provided the original author(s) and source are credited.

\section{References}

[1] Gilliland, G.; Perrin, S.; Blanchard, K.; Bunn, H. F. Analysis of cytokine mRNA and DNA: Detection and quantitation by competitive polymerase chain reaction. Proc. Natl. Acad. Sci. USA 1990, 87, 2725-2729.

[2] Park, S. J.; Taton, T. A.; Mirkin, C. A. Array-based electrical detection of DNA with nanoparticle probes. Science 2002, 295, 1503-1506.

[3] Hahm, J.; Lieber, C. M. Direct ultrasensitive electrical detection of DNA and DNA sequence variations using nanowire nanosensors. Nano Lett. 2004, 4, 51-54.

[4] Laure, F.; Rouzioux, C.; Veber, F.; Jacomet, C.; Courgnaud, V.; Blanche, S.; Burgard, M.; Griscelli, C.; Brechot, C. Detection of HTV1 DNA in infants and children by means of the polymerase chain reaction. The Lancet 1988, 332, 538-541.

[5] Dougan, J. A.; Karlsson, C.; Smith, W. E.; Graham, D. Enhanced oligonucleotide-nanoparticle conjugate stability using thioctic acid modified oligonucleotides. Nucleic Acids Res. 2007, 35, 3668-3675.

[6] Husale, S.; Persson, H. H. J.; Sahin, O. DNA nanomechanics allows direct digital detection of complementary DNA and microRNA targets. Nature 2009, 462, 1075-1078.

[7] Haiss, W.; Thanh, N. T. K.; Aveyard, J.; Fernig, D. G. Determination of size and concentration of gold nanoparticles from UV-Vis spectra. Anal. Chem. 2007, 79, 4215-4221.

[8] Elghanian, R.; Storhoff, J. J.; Mucic, R. C.; Letsinger, R. L.; Mirkin, C. A. Selective colorimetric detection of polynucleotides based on the distance-dependent optical properties of gold nanoparticles. Science 1997, 277, 1078-1081.

[9] Lin, C. X.; Xie, M. Y.; Chen, J. J. L.; Liu, Y.; Yan, H. Rolling-circle amplification of a DNA nanojunction. Angew. Chem. Int. Ed. 2006, 45, 7537-7539.

[10] De, M.; Ghosh, P. S.; Rotello, V. M. Applications of nanoparticles in biology. Adv. Mater. 2008, 20, 4225-4241.

[11] Marques, P. R. B. D.; Lermo, A.; Campoy, S.; Yamanaka, H.; Barbe, J.; Alegret, S.; Pividori, M. I. Double-tagging polymerase chain reaction with a thiolated primer and electrochemical genosensing based on gold nanocomposite sensor for food safety. Anal. Chem. 2009, 81, 1332-1339.

[12] Xu, X. Y.; Rosi, N. L.; Wang, Y. H.; Huo, F. W.; Mirkin, C. A. Asymmetric functionalization of gold nanoparticles with oligonucleotides. J. Am. Chem. Soc. 2006, 128, 9286-9287.

[13] Rosi, N. L.; Giljohann, D. A.; Thaxton, C. S.; Lytton-Jean, A. K. R.; Han, M. S.; Mirkin, C. A. Oligonucleotide-modified gold nanoparticles for intracellular gene regulation. Science 2006, 312, 1027-1030.

[14] Kim, E. Y.; Stanton, J.; Vega, R. A.; Kunstman, K. J.; Mirkin, C. A.; Wolinsky, S. M. A real-time PCR-based method for determining the surface coverage of thiol-capped oligonucleotides bound onto gold nanoparticles. Nucleic Acids Res. 2006, 34, e54.

[15] Naik, R. R.; Jones, S. E.; Murray, C. J.; McAuliffe, J. C.; Vaia, R. A.; Stone, M. O. Peptide templates for nanoparticle synthesis derived from polymerase chain reaction-driven phage display. Adv. Funct. Mater. 2004, 14, 25-30. 
[16] VanGuilder, H. D.; Vrana, K. E.; Freeman, W. M. Twentyfive years of quantitative PCR for gene expression analysis. Biotechniques 2008, 44, 619-626.

[17] Liu, J. W.; Lu, Y. Preparation of aptamer-linked gold nanoparticle purple aggregates for colorimetric sensing of analytes. Nat. Protoc. 2006, 1, 246-252.

[18] Sharma, J.; Chhabra, R.; Cheng, A.; Brownell, J.; Liu, Y.; Yan, H. Control of self-assembly of DNA tubules through integration of gold nanoparticles. Science 2009, 323, 112-116.

[19] Zhang, J.; Liu, Y.; Ke, Y.; Yan, H. Periodic square-like gold nanoparticle arrays templated by self-assembled 2D DNA nanogrids on a surface. Nano Lett. 2006, 6, 248-251.

[20] Sharma, J.; Chhabra, R.; Liu, Y.; Ke, Y.; Yan, H. DNA templated self-assembly of two-dimensional and periodical gold nanoparticle arrays. Angew. Chem. Int. Ed. 2006, 45, 730-735.

[21] Chen, C.; Song, G. T.; Ren, J. S.; Qu, X. G. A simple and sensitive colorimetric $\mathrm{pH}$ meter based on DNA conformational switch and gold nanoparticle aggregation. Chem. Commun. 2008, 6149-6151.
[22] Verma, A.; Srivastava, S.; Rotello, V. M. Modulation of the interparticle spacing and optical behavior of nanoparticle ensembles using a single protein spacer. Chem. Mater. 2005 , 17, 6317-6322.

[23] Srivastava, S.; Frankamp, B. L.; Rotello, V. M. Controlled plasmon resonance of gold nanoparticles self-assembled with PAMAM dendrimers. Chem. Mater. 2005, 17, 487-490.

[24] Kalluri, J. R.; Arbneshi, T.; Khan, S. A.; Neely, A.; Candice, P.; Varisli, B.; Washington, M.; McAfee, S.; Robinson, B.; Banerjee, S.; Singh, A. K.; Senapati, D.; Ray, P. C. Use of gold nanoparticles in a simple colorimetric and ultrasensitive dynamic light scattering assay: Selective detection of arsenic in groundwater. Angew. Chem. Int. Ed. 2009, 48, 9668-9671.

[25] Liu, J. W.; Lu, Y. Accelerated color change of gold nanoparticles assembled by DNAzymes for simple and fast colorimetric $\mathrm{Pb}^{2+}$ detection. J. Am. Chem. Soc. 2004, 126, 12298-12305. 